\title{
Cultural Sensitivity of Japanese Nurses: Exploring Clinical Application of the Intercultural Sensitivity Scale
}

\author{
Tomiko Toda*, Mitsue Maru \\ Konan Women's University, Kobe, Japan \\ Email: *t.toda@konan-wu.ac.jp
}

How to cite this paper: Toda, T. and Maru, M. (2018) Cultural Sensitivity of Japanese Nurses: Exploring Clinical Application of the Intercultural Sensitivity Scale. Open Journal of Nursing, 8, 640-655. https://doi.org/10.4236/ojn.2018.89048

Received: July 17, 2018

Accepted: September 11, 2018

Published: September 14, 2018

Copyright $\odot 2018$ by authors and Scientific Research Publishing Inc. This work is licensed under the Creative Commons Attribution International License (CC BY 4.0).

http://creativecommons.org/licenses/by/4.0/

\section{(c) (i) Open Access}

\begin{abstract}
Unlike Western countries, Asian countries have a brief history of caring for patients with various cultural and linguistic backgrounds. Healthcare professionals face difficulty in providing care to foreign patients. Presumably, those with higher cultural sensitivity possess higher cultural competency, and cultural indicators are associated with personal factors, such as interest in or learning experience of foreign languages. We examined correlations between Intercultural Sensitivity Scale (ISS) and Cultural Competence in Nursing Scale (CCNS) scores in Japanese nurses and discussed implications of our findings in increasing cultural sensitivity in countries with limited exposure to foreign culture. A questionnaire survey on ISS, CCNS, and personal factors was conducted among 156 nurses. Correlations among the two scales and personal factors were analyzed. Total ISS scores were comparable with previously reported scores. ISS and CCNS scores were moderately correlated. ISS subscale scores were moderately correlated with the learning experience of foreign languages. Nurses most commonly learned English; most foreign patients were Chinese. Experiences of providing care to foreign patients were not related to cultural sensitivity. The lowest ISS score was obtained in "interaction confidence" subscale. Languages used by foreign patients did not match languages that nurses had interest in or had learned; this may contribute to their low confidence in interacting with foreigners. Nurses in a country with limited exposure to different cultures need educational intervention for providing care to foreigners regardless of their cultural experiences. ISS may be useful to identify nurses who need further education to foster confidence while interacting with foreigners.
\end{abstract}

\section{Keywords}

Intercultural Sensitivity, Cultural Competence, Foreign Patients 


\section{Introduction}

With the growing medical tourism industry and the surging number of foreign tourists and workers, there is an increase in the exposure of healthcare professionals to foreigners in the clinical settings in many Asian countries [1]. Unlike Western countries, Asian countries have a brief history of providing care to patients with various cultural and linguistic backgrounds. Healthcare professionals undoubtedly face difficulties in providing care to patients with different ethnic backgrounds. Yet, there have been a few studies in the literature on this topic in Asian countries [2] [3] [4].

The Visit Japan policy of 2011 contributed to the sudden rise in the number of foreigners visiting Japan, with the number exceeding 28 million in 2017. Approximately $30 \%$ of medical institutions were reported to have encountered difficulties in dealing with foreign patients due to insufficient cultural competency of nurses [5].

"Cultural competency" is acquired through the process of awareness, knowledge, sensitivity, and application in practice, and "cultural sensitivity," which indicates a positive emotion toward understanding and appreciating cultural differences, is considered the most essential among these factors [6]. Chen and Starosta have developed the Intercultural Sensitivity Scale (ISS) comprising of the following five subscales: 1) interaction engagement, 2) respect for cultural differences, 3) interaction confidence, 4) interaction enjoyment, and 5) interaction attentiveness [7]. ISS has been used in studies of medical professionals in Turkey and the USA [8] [9] [10] and has been translated into Japanese (Japanese ISS) by Kuwano, who established the reliability measured using the Cronbach alpha and face validity of the Japanese ISS among Japanese nurses [4].

Cultural competency refers to the nursing skill of providing appropriate care to patients with diverse cultural backgrounds, and a set of scales have been developed in Western countries to measure such skills [6] [11]. These scales were primarily intended to measure skills of nurses who provide direct care to minorities in multicultural societies. The Cultural Competence in Nursing Scale (CCNS), developed by Sugiura, measures the cultural competency of Japanese nurses [12]. This scale is based on the Cultural Competence Model of Care developed by Campinha-Bacote and comprises the following five subscales: 1) awareness of one's own culture, 2) approach-avoidance tendency, 3) general cultural knowledge, 4) specific cultural knowledge, and 5) cultural skills.

Several personal factors were identified to be related to cultural/intercultural sensitivities. In a validation study, CCNS scores were associated with the number of foreign patients cared for, educational achievement, length of clinical experience, and interest in or learning experience of foreign languages as well as higher levels of proficiency in foreign languages, overseas living experiences, and having chances to meet foreigners off duty [12].

Conversely, in studies of Turkish nurses, different results regarding the association between cultural sensitivity and personal factors, such as learning expe- 
riences of foreign languages, have been reported using ISS [8] [9]. Another study investigating healthcare professional students' cultural sensitivity after being exposed to different cultures has reported significant changes of cultural sensitivities, which may be related to reflective activities, but not personal factors [10].

The conceptual framework of this research is shown in Figure 1. Healthcare professionals with higher cultural sensitivity are presumed to possess higher cultural competency, and these cultural indicators are associated with personal factors, such as interest in studying foreign languages. This study aimed to examine the correlation between cultural sensitivity and competency among Japanese nurses and to discuss implications of our findings for increasing cultural sensitivity among nurses in a country with limited exposure to different cultures.

\section{Study Method}

\subsection{Setting}

The study was performed at a general hospital (Hospital A) with $>500$ bed capacity located in the central part of a metropolitan city, with a relatively high number of foreign patients.

\subsection{Participants}

The inclusion criteria were nurses working at Hospital A, with over 1-year clinical experience of providing care to foreign patients. The exclusion criterion was nurses with less than one-year clinical experience.

The director of the nursing department at Hospital A was approached for the approval of the study. Upon receiving approval, 10 copies of a questionnaire were distributed by the nursing department to 18 wards, and nurses who met the subject inclusion criteria were selected by the nurse managers of each ward.

\subsection{Survey Items}

An 85-item survey comprised personal factors, ISS scores, and CCNS scores as described below.

Demographic data included 15 items: age (20 - 29 years, 30 - 39 years, and 40 59 years); sex; educational achievement; years of clinical experience $(<10$ years, 10 - 14 years, and $\geq 15$ years); years of employment at Hospital A; experience of caring for foreign patients; interest in or learning experience of foreign languages; number of foreign patients cared for $(<5,6-10$, and $>11)$; country of origin and nationality; difficulties experienced while caring for foreign patients; overseas living experiences; opportunities of meeting foreigners off duty; interest in learning foreign languages; having previously or currently learned foreign languages; and having interest in or having learned foreign languages with language proficiency levels based on the Common European Framework of Reference for Languages (CEFR) standards. 


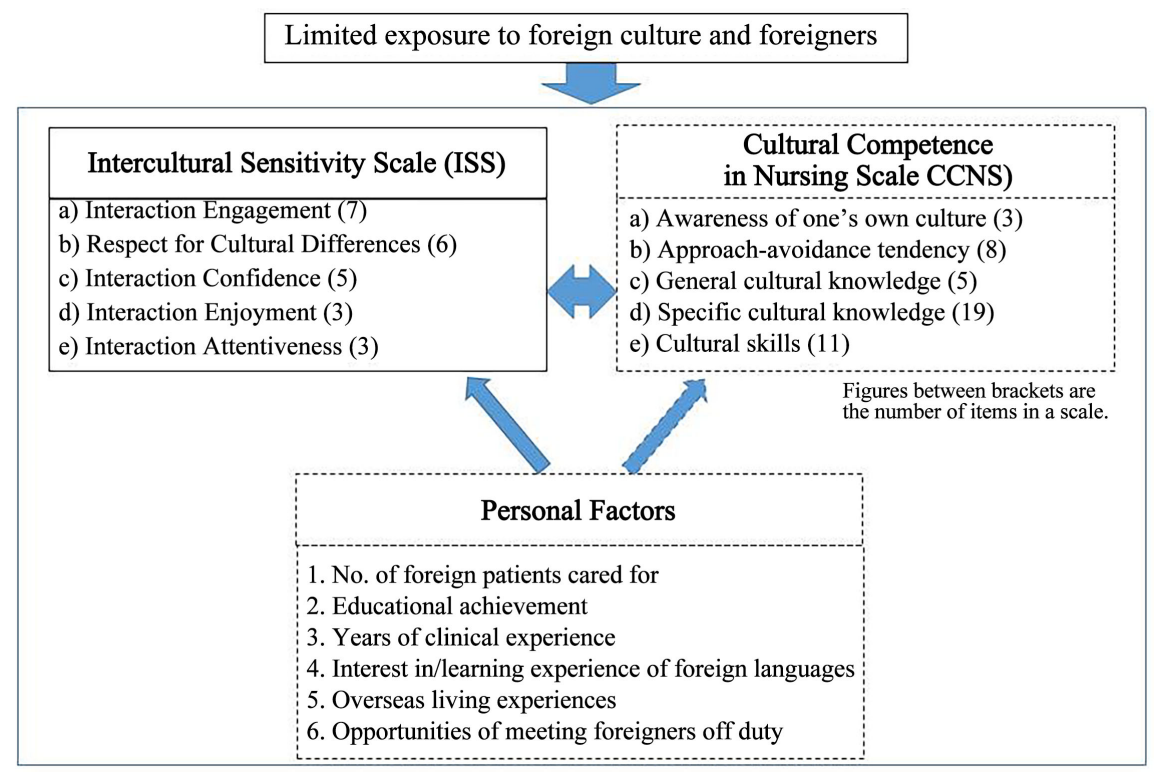

Figure1. Conceptual Framework of factors influencing cultural sensitivity.

\subsubsection{Intercultural Sensitivity}

ISS comprises five subscales (Figure 1) with 24 items [7]. A five-point Likert scale from 5 (totally agree) to 1 (completely disagree), with scores ranging from 24 to 120 points, was used to assess responses to each item. Higher scores indicated stronger positive emotion toward cultural differences.

\subsubsection{Cultural Competence in Nursing}

CCNS comprises five subscales (Figure 1) with 46 items. The responses are expressed in a four-point Likert scale, ranging from 1 (no) to 4 (yes), and total score ranges from 46 to 184 . Higher scores indicate a higher cultural competence in nursing.

CCNS was based on the Cultural Competence Model of Care developed by Campinha-Bacote. This model is a broad concept involving multicultural societies, which includes socioeconomic status, religion, and sexual orientation. Therefore, CCNS was developed by a Japanese nurse for specifically measuring the cultural competency of Japanese nurses.

The consent to use ISS, Japanese ISS, and CCNS for the purpose of this study was obtained by the authors.

\section{Survey Method}

A total of 180 anonymous questionnaires within envelopes were distributed to all 18 wards in the nursing department of Hospital A. Respondents were requested to fill out the questionnaire, seal it, and then post it in the box in each ward. Then, questionnaires were gathered and forwarded to the authors.

\subsection{Survey Period}

The survey was conducted from July to August 2017. 


\subsection{Analysis Method}

\subsubsection{Participant Characteristics}

Descriptive statistics were conducted for all the variables. Since the number of items included in subscales differed for both scales, the mean score and standard deviation were calculated for each subscale.

\subsubsection{Correlation between Participant Characteristics, Japanese ISS, and CCNS}

To examine the correlation between participant characteristics and the scores of the two scales, participants were divided into two groups according to 1) overseas living experiences, 2) opportunity to meet foreigners off duty, and 3) interest in or learning experience of foreign languages. t-test or Mann-Whitney U-test was used to determine the statistical differences between Japanese ISS and CCNS scores among the two groups depending on the distribution of the variance. In addition, educational achievements were stratified into two groups of nursing diploma, and Bachelor or Master of Science and operational titles were stratifies into two groups of staff nurses and supervisory positions.

Kruskal-Wallis test was used to determine the differences between Japanese ISS and CCNS scores among the three demographic and clinical variables (age, clinical experience, and number of foreign patients cared for).

Spearman's correlation coefficient was used to measure total Japanese ISS scores, total CCNS scores, and participant characteristics related to exposure to different cultures (number of foreign patients cared for, overseas living experiences, opportunities to meet foreigners off duty, and interest in or learning experience of foreign languages). Correlation coefficients between total scores of the two scales as well as those between subscales scores of the two scales were tabulated to examine the concurrent validity.

A statistical significance level was set at $1 \%$ because of multiple comparisons. SPSS $25.0 \mathrm{~J}$ for Windows (IBM Japan, Tokyo, Japan) was used for statistical analyses.

\section{Ethical Considerations}

The respondents indicated that their participation was voluntary and that they were free to withdraw at any point without penalty. The anonymity and confidentiality of data were guaranteed. The purpose of the survey and the statistical processing of survey results were described on the cover page of the self-administered questionnaire. This study was approved by the Ethics Committee of the university that the authors are affiliated (Approval number 2016025) to as well as the institution at which the study was conducted (Approval number 2017-029).

\section{Results}

\subsection{Response Rate and Handling of Missing Values}

A total of 180 copies of questionnaires were distributed. The response rate was 
$86.7 \%$, with a total of 126 valid responses. However, 30 missing values were identified in some of the scale item. After consulting with the scale authors, a mean value of the item was assigned to the missing values and scores were analyzed.

\subsection{Respondent Characteristics}

Demographic characteristics of the respondents are presented in Table 1. A majority of the participants were $<40$ years of age with nursing diploma, and over two-thirds were staff nurses with $<15$ years of clinical experience. In terms of experience in caring for foreign patients, over $50 \%$ reported to have previously cared for five or more foreign patients from more than 34 countries and regions, of which majority were mainly from China. With regard to exposure to different cultures, $12 \%$ of the respondents had lived overseas and $17 \%$ had had an opportunity to meet foreigners off duty.

In terms of whether or not they had any interest in or learning experience of foreign languages, nearly half of the respondents provided affirmative responses. In total, 73 participants responded to have interest in learning English, of which 56 were at the A level (beginner level) according to CEFR. However, nearly $90 \%$ of the respondents did not have any interests in or learning experiences of foreign languages or their English proficiency was at the basic level.

\subsection{Correlation between the Japanese ISS Score and Participant Characteristics}

The mean total score of Japanese ISS was 76.3. Among five subscales, "respect for cultural differences" had the highest subscale score, while "interaction confidence" had the lowest score (Table 2). "Interaction confidence" had a mean score of 2.1 or less in all five items. "I feel confident when interacting with people from different cultures" had the lowest mean score among all the items, with both median and mode at 2.0 (Appendix 1).

These ISS subscale scores were associated with participants' level of exposure to different cultures. Significant but weak correlations were observed between total Japanese ISS scores and "overseas living experiences," "opportunity to meet foreigners off duty," and "interest in or learning experience of foreign languages" (Table 3). However, total Japanese ISS score was not associated with participants' age, educational achievement, years of clinical experience, operational titles, and number of foreign patients cared for.

\subsection{Correlation between Japanese ISS and CCNS Scores}

Total mean CCNS score was 99.3, with “awareness of one’s own culture” having the highest mean subscale score and "specific cultural knowledge" having the lowest score (Table 4, Appendix 2).

A moderate correlation was observed between total Japanese ISS scores and total CCNS score (Table 3 ). Among subscales of CCNS, only one subscale "ap- 
proach avoidance tendency" shows moderate correlation with total Japanese ISS scores (Table 5).

Total Japanese ISS score was also weakly correlated with four of the five CCNS subscales (Table 5). Among subscales of ISS, "Interaction engagement" was moderately correlated with total CCNS score. Weak correlations were observed between total CCNS scores and exposure to different cultures, such as "overseas living experiences," "opportunity to meet foreigners off duty," and "number of foreign patients cared for" (Table 5).

Table 1. Demographic characteristics $(n=156)$.

\begin{tabular}{|c|c|c|}
\hline & $\mathrm{n}$ & $\%$ \\
\hline \multicolumn{3}{|l|}{ Sex } \\
\hline Female & 154 & 98.7 \\
\hline Male & 2 & 1.3 \\
\hline \multicolumn{3}{|l|}{ Age } \\
\hline $20-29$ & 55 & 35.3 \\
\hline $30-39$ & 40 & 25.6 \\
\hline $40-59$ & 61 & 39.1 \\
\hline \multicolumn{3}{|l|}{ Educational achievement } \\
\hline Nursing Diploma & 96 & 61.5 \\
\hline Bachelor/Master of Science & 59 & 37.8 \\
\hline Non-Responders & 1 & 0.6 \\
\hline \multicolumn{3}{|c|}{ Years of clinical experience (year) } \\
\hline Less than 10 & 47 & 30.1 \\
\hline $10-14$ & 48 & 30.8 \\
\hline$\geqq 15$ & 57 & 36.6 \\
\hline Non-Responders & 4 & 2.6 \\
\hline \multicolumn{3}{|c|}{ Mode 3.0, median 10.0, mean $11.6 \pm 8.3$, range $30.0-1.0$} \\
\hline \multicolumn{3}{|c|}{ Years of working experience at Hospital A (year) } \\
\hline Less than 5 & 83 & 53.2 \\
\hline $5-9$ & 19 & 12.2 \\
\hline $10-14$ & 24 & 15.4 \\
\hline$\geqq 15$ & 27 & 17.3 \\
\hline Non-Responders & 3 & 1.9 \\
\hline \multicolumn{3}{|c|}{ Mode 3.0, median 5.0, mean $7.7 \pm 6.7$, range $30.0-0.0$} \\
\hline \multicolumn{3}{|l|}{ Operational titles } \\
\hline Staff nurse & 116 & 74.4 \\
\hline Supervisory position & 35 & 22.4 \\
\hline Non-Responders & 5 & 3.2 \\
\hline \multicolumn{3}{|l|}{ Wards } \\
\hline Internal medical ward & 44 & 28.2 \\
\hline Surgical ward & 24 & 15.4 \\
\hline
\end{tabular}




\section{Continued}

\begin{tabular}{|c|c|c|}
\hline Outpatient clinic & 20 & 12.8 \\
\hline ICU/NICU & 18 & 11.5 \\
\hline Operating room & 10 & 6.4 \\
\hline Hospice & 8 & 5.1 \\
\hline Maternity ward & 7 & 4.5 \\
\hline Mixed ward & 6 & 3.8 \\
\hline Pediatric ward & 5 & 3.2 \\
\hline Others & 14 & 9.0 \\
\hline \multicolumn{3}{|l|}{ No. of foreign patients cared for } \\
\hline$\leqq 5$ & 67 & 42.9 \\
\hline $6-10$ & 48 & 30.8 \\
\hline$\geqq 11$ & 37 & 23.7 \\
\hline Non-Responders & 4 & 2.6 \\
\hline \multicolumn{3}{|c|}{ Experiences of difficulties in caring for foreign patients } \\
\hline Yes & 144 & 92.3 \\
\hline None & 9 & 5.8 \\
\hline Non-Responders & 3 & 1.9 \\
\hline \multicolumn{3}{|c|}{ No. of foreign patients cared for by region (multiple answers) } \\
\hline Eastern Asia & 256 & \\
\hline South-eastern Asia & 105 & \\
\hline Northern America & 88 & \\
\hline Southern Asia & 56 & \\
\hline Europe & 51 & \\
\hline Latin America and the Caribbean & 17 & \\
\hline Western Asia & 3 & \\
\hline Oceania & 3 & \\
\hline Unknown & 6 & \\
\hline \multicolumn{3}{|c|}{ Overseas living experiences ( $\geqq 3$ months) } \\
\hline Yes & 19 & 12.2 \\
\hline None & 135 & 86.5 \\
\hline Non-Responders & 2 & 1.3 \\
\hline \multicolumn{3}{|c|}{ Opportunities of meeting foreigners off duty } \\
\hline Yes & 26 & 16.7 \\
\hline None & 128 & 82.1 \\
\hline Non-Responders & 2 & 1.3 \\
\hline \multicolumn{3}{|c|}{ Interest in or learning experience of foreign languages (multiple answers) } \\
\hline Yes $^{*}$ & 73 & 46.8 \\
\hline None & 80 & 51.3 \\
\hline Non-Responders & 3 & 1.9 \\
\hline
\end{tabular}

${ }^{*}$ English $(n=68)$, Chinese $(n=4)$, French German Spanish Korean, Indonesian Nepali Vietnamese (each $1)$. 
Table 2. Total and subscales scores of ISS $(n=156)$.

\begin{tabular}{lcccc}
\hline & Intercultulal Sensitivitiy Scale & Mean & Min & Max \\
\hline & Total Score of ISS & $76.33 \pm 8.40$ & 50.00 & 101.00 \\
& Respect for Cultural Differences & $3.79 \pm 0.42$ & 2.83 & 5.00 \\
Subscales & Interaction Engagement & $3.34 \pm 0.45$ & 2.00 & 4.57 \\
& Interaction Attentiveness & $3.27 \pm 0.51$ & 1.67 & 4.67 \\
& Interaction Enjoyment & $3.26 \pm 0.68$ & 1.67 & 5.00 \\
\hline
\end{tabular}

Table 3. Correlation between the Japanese ISS score and participant characteristics $(n=148)$.

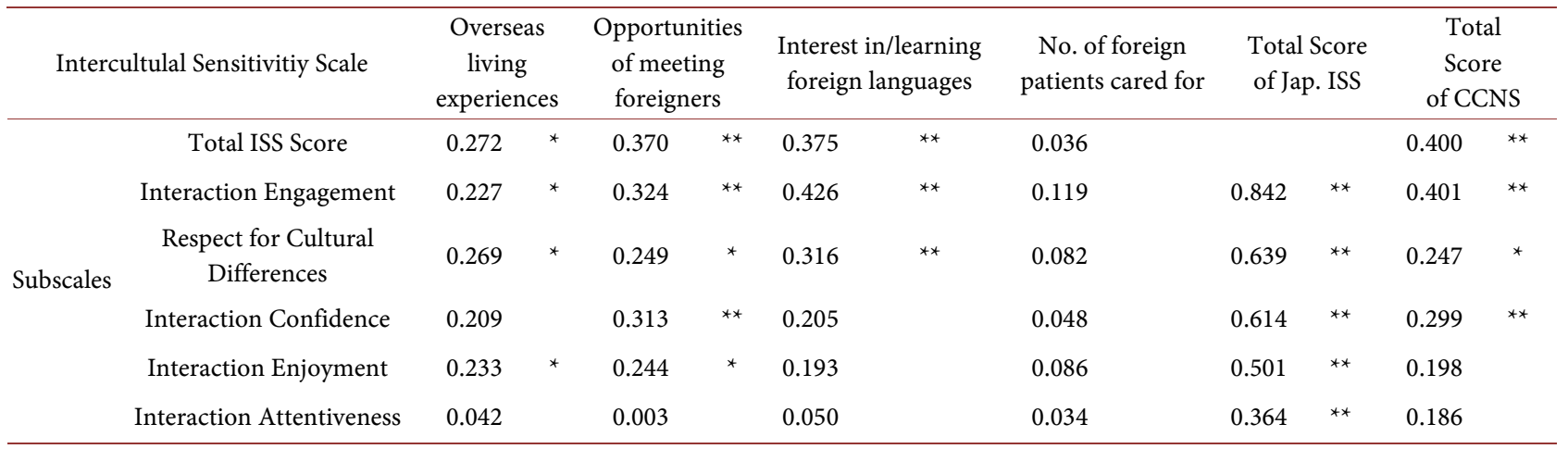

${ }^{*} \mathrm{p}<0.01,{ }^{* *} \mathrm{p}<0.001$.

Table 4. Total and subcales scores of CCNS $(n=156)$.

\begin{tabular}{ccccc}
\hline & Cultural Competence in Nursing Scale & Mean & Min & Max \\
\hline & Total Score of CCNS & $99.33 \pm 16.47$ & 57.00 & 142.84 \\
Awareness of one's own culture & $2.55 \pm 0.70$ & 1.00 & 4.00 \\
Approach-avoidance tendency & Cultural skills & $2.49 \pm 0.42$ & 1.50 & 3.88 \\
& General cultural knowledge & $2.47 \pm 0.50$ & 1.00 & 3.82 \\
& Specific cultural knowledge & $2.03 \pm 0.50$ & 1.00 & 3.40 \\
\hline
\end{tabular}

Table 5. Correlation between CCNS and participant characteristics $(n=148)$.

\begin{tabular}{|c|c|c|c|c|c|c|c|c|c|c|c|c|c|}
\hline \multirow{2}{*}{\multicolumn{2}{|c|}{$\begin{array}{l}\text { Cultural Competence } \\
\text { in Nursing Scale (CCNS) }\end{array}$}} & \multicolumn{8}{|c|}{ Personal experience/iterest } & \multirow{2}{*}{\multicolumn{2}{|c|}{$\begin{array}{l}\text { Total ISS } \\
\text { Score }\end{array}$}} & \multirow{2}{*}{\multicolumn{2}{|c|}{$\begin{array}{c}\text { Total CCNS } \\
\text { Score }\end{array}$}} \\
\hline & & \multicolumn{2}{|c|}{$\begin{array}{c}\text { Overseas living } \\
\text { experiences }\end{array}$} & \multicolumn{2}{|c|}{$\begin{array}{l}\text { Opportunities of meeting } \\
\text { foreigners }\end{array}$} & \multicolumn{2}{|c|}{$\begin{array}{c}\text { No. of foreign } \\
\text { patients cared for }\end{array}$} & \multicolumn{2}{|c|}{$\begin{array}{l}\text { Interest in/learning } \\
\text { foreign languages }\end{array}$} & & & & \\
\hline \multirow{6}{*}{$\begin{array}{c}\text { CCNS } \\
\text { Subscales }\end{array}$} & CCNS Total Score & 0.355 & $* *$ & 0.290 & $* *$ & 0.315 & ** & 0.233 & * & 0.400 & ** & & \\
\hline & $\begin{array}{c}\text { Awareness of } \\
\text { one's own culture }\end{array}$ & 0.203 & & 0.159 & & 0.095 & & 0.091 & & 0.280 & * & 0.393 & $* *$ \\
\hline & $\begin{array}{l}\text { Approach-avoidance } \\
\text { tendency }\end{array}$ & 0.281 & * & 0.184 & & 0.166 & & 0.194 & & 0.420 & ** & 0.521 & $* *$ \\
\hline & $\begin{array}{l}\text { General cultural } \\
\text { knowledge }\end{array}$ & 0.243 & * & 0.206 & & 0.221 & * & 0.279 & * & 0.128 & & 0.674 & $* *$ \\
\hline & $\begin{array}{l}\text { Specific cultural } \\
\text { knowledge }\end{array}$ & 0.368 & $* *$ & 0.270 & * & 0.252 & * & 0.268 & * & 0.229 & * & 0.864 & $* *$ \\
\hline & Cultural skills & 0.001 & & 0.055 & & 0.219 & * & 0.016 & & 0.326 & ** & 0.587 & ** \\
\hline
\end{tabular}

${ }^{*} \mathrm{p}<0.01,{ }^{* *} \mathrm{p}<0.001,{ }^{*}$ ISS $=$ Intercultural Sensitivity Scale. 


\section{Discussion}

With the expanding globalization worldwide, including Asian countries, it is essential for every nurse to enhance their cultural sensitivity in providing cultural congruent care to culturally diverse patients. This study explored cultural sensitivities of nurses working at a hospital with a relatively high number of foreign patients. Our findings highlight the necessity of continuing educational program regarding the cultural competence of nurses.

\subsection{Cultural Sensitivity of Japanese Nurses}

Total mean Japanese ISS score among Japanese nurses was comparable with that in previous studies [4]. However, score for "interaction confidence" subscale was the lowest in this study, with the lowest average in "I feel confident when interacting with people from different cultures," suggesting low confidence levels while interacting with foreigners in daily life.

Our findings are consistent with those of a previous study that demonstrated significant correlations between ISS total score and foreign language proficiency as well as foreign language interests or learning experiences [8]. English was the foreign language that almost all the participants showed interest in or had learning experiences with. However, a majority of foreign patients were Chinese, whereas the rest were from a range of other countries and regions. In a previous survey regarding the use of interpreters in Japanese hospitals, $40 \%$ of the medical interpreters used Asian languages, such as Chinese and Vietnamese, while only 10\% used English [13] [14].

In the past, although most of the foreign tourists were from Western countries [15], economic growth in Asian countries and increase in low-cost carriers have contributed to the advancement of tourism industry in Asia [16]. In addition, Chinese, followed by Korean, Filipino, Vietnamese, and Brazilian, are reported as the most dominant non-Japanese residents in Japan [17]. Both basic and continuing nursing education have not been able to cope with the rapid increase of tourists and non-Japanese residents as languages used by the foreign patients did not seem to match languages that participants had interest in or had a learning experience with. This discrepancy may contribute to participants' low confidence while interacting with foreign patients.

\subsection{Correlation between Cultural Sensitivity and Cultural Competency}

CCNS is focused on "how professionals view people in their care" [6] and includes not only interactions but also the competency to provide professional care. A previous study using CCNS has shown that the nursing autonomy of providing care to foreign patients was significantly related to cultural competency [4]. Cultural sensitivity is believed to be an essential characteristic of nurses in providing care to foreign patients.

ISS was initially developed to measure intercultural communication skills, and 
the subscales also focused on interactions, such as "interaction confidence." In this study, moderate correlation between ISS and CCNS, including subscale of approach-avoidance tendency, was identified. This finding suggested that a part of cultural competency, possibly "general intercultural communication skills," is related to cultural sensitivity.

\subsection{Cultural Sensitivity and Personal Factors}

In this study, personal factors and cultural sensitivities did not have strong correlations with neither ISS nor CCNS. Furthermore, other significant personal factors were not identified, except learning experiences of foreign language. This suggests that the level of exposure to different cultures may not be related to cultural sensitivity. Although a study has suggested that reflective activities with a mentor after exposure to different cultures may improve cultural sensitivities of students [10], more studies are required to explore the meaning of learning experiences of different cultures or other qualitative factors, such as nurses' perceptions of caring for foreign patients.

\subsection{Clinical Implication to Improve Cultural Sensitivity among Nurses with Limited Exposure to Different Cultures}

This study is the first to explore nursing competency using both CCNS and ISS. With a long history of Hospital A in providing healthcare to foreign patients in Japan, Japanese nurses in general may have less cultural sensitivity and lower cultural competence than nurses in this study. Because the validity of cultural sensitivity scales for Asian nurses has not been reported in detail [3], ISS may be useful as a proxy scale to measure a part of cultural competency for this population.

Among ISS subscales, the lowest score was found in "interaction confidence." In this subscale, all items are related to communication with people from different cultures. However, no significant correlation was noted between this communication confidence and the number of foreign patients cared for.

Therefore, a continuing education should be established for nurses regardless of the clinical experiences or the number of foreign patients cared for by screening their perception of cultural competency with this questionnaire. In addition, to increase cultural sensitivity of nurses in a country with limited exposure to different cultures, educational program should be designed for fostering confidence based on the results of nurses' perception, especially while interacting with people from different cultures.

\section{Conclusion}

In this study, the cultural sensitivity of nurses was comparable with that reported in previous studies; however, there was lack of confidence in interacting with people from different cultures. Our findings suggest that nurses in a country with limited exposure to different cultures require educational intervention re- 
gardless of their cultural experiences, including caring for foreign patients. ISS may be useful to identify nurses who need further education for fostering their confidence while interacting with foreigners.

\section{Acknowledgements}

The authors would like to express our sincere gratitude to all the nurses at Hospital A and those who supported us in this study. We also deeply appreciate Professor Kiyoko Makimoto of Konan Women's University Graduate School, who has guided us in conducting this research.

\section{Competing Interests}

The authors declare that they have no competing interests.

\section{Authors' Contributions}

TT was responsible for data collection and analysis and drafting of the manuscript. MM critically revised the manuscript. Both authors have read and approved the final manuscript.

\section{References}

[1] Moghavvemi, S., Ormond, M., Musa, G., Isa, C.R.M., Thirumoorthi, T., Mustapha, M.Z.B. and Chandy, J.J.C. (2017) Connecting with Prospective Medical Tourists Online: A Cross-Sectional Analysis of Private Hospital Websites Promoting Medical Tourism in India, Malaysia and Thailand. Tourism Management, 58, 154-163. https://doi.org/10.1016/j.tourman.2016.10.010

[2] Ahn, J.W. (2017) Structural Equation Modeling of Cultural Competence of Nurses Caring for Foreign Patients. Asian Nursing Research, 11, 65-73. https://doi.org/10.1016/j.anr.2017.03.001

[3] Chae, D.H. and Lee, C.Y. (2014) Development and Psychometric Evaluation of the Korean Version of the Cultural Competence Scale for Clinical Nurses. Asian Nursing Research, 8, 305-312. https://doi.org/10.1016/j.anr.2014.06.004

[4] Kuwano, N., Fukuda, H. and Murashima, S. (2016) Factors Affecting Professional Autonomy of Japanese Nurses Caring for Culturally and Linguistically Diverse Patients in a Hospital Setting in Japan. Journal of Transcultural Nursing, 27, 567-573. https://doi.org/10.1177/1043659615587588

[5] Kansai Bureau of Economy, Trade and Industry (2017) Project of Improving Acceptance of Foreign Tourists in Medical Sectors, 2017. (in Japanese) http://wwwtb.mlit.go.jp/kinki/content/000031160.pdf

[6] Papadopoulos, I., Shea, S., Taylor, G., Pezzella, A. and Foley, L. (2016) Developing Tools to Promote Culturally Competent Compassion, Courage, and Intercultural Communication in Healthcare. Journal of Compassionate Health Care, 3, 2. https://doi.org/10.1186/s40639-016-0019-6

[7] Chen, G.M. and Starosta, W.J. (2000) The Development and Validation of the Intercultural Sensitivity Scale. Human Communication, 3, 1-15.

[8] Uzun, Ö. and Sevinç, S. (2015) The Relationship between Cultural Sensitivity and Perceived Stress among Nurses Working with Foreign Patients. Journal of Clinical Nursing, 24, 3400-3408. https://doi.org/10.1111/jocn.12982 
[9] Yilmaz, M., Toksoy, S., Direk, Z.D., Bezirgan, S. and Boylu, M. (2017) Cultural Sensitivity among Clinical Nurses: A Descriptive Study. Journal of Nursing Scholarship, 49, 153-161. https://doi.org/10.1111/jnu.12276

[10] Richards, C.A. and Doorenbos, A.Z. (2016) Intercultural Competency Development of Health Professions Students during Study Abroad in India. Journal of Nursing Education and Practice, 6, 89. https://doi.org/10.5430/jnep.v6n12p89

[11] Campinha-Bacote, J. (1999) A Model and Instrument for Addressing Cultural Competence in Health Care. Journal of Nursing Education, 38, 203-207.

[12] Sugiura, K. (2003) Survey-Based Analysis of Cultural Competence in Nursing and its Predictors: Comparison between Nurses Who Were Japan Overseas Cooperation Volunteers and Nurses Working at Municipal Hospitals. Japanese Academy of Nursing Science, 23, 22-36. https://doi.org/10.5630/jans1981.23.3_22

[13] Morita, N. (2017) The Roles of Medical Interpreters between Different Cultures and Languages. Journal of the Japanese Society of Travel and Health, 11, 67-69. (in Japanese)

[14] Sawada, M. (2017) The Possibilities and Goals of Remote Medical Interpreters. Journal of the Japanese Society of Travel and Health, 11, 70-73. (in Japanese)

[15] Japan National Tourism Organization. Trends of Tourism in Japan, 20 November 2014. (in Japanese), http://www.soumu.go.jp/main_content/000324742.pdf

[16] Wu, C. and Hayashi, Y. (2014) The Effect of LCCs Operations and Scheduled Services Deregulation on Air Charter Business in Japan. Journal of Transport Geography, 41, 37-44. https://doi.org/10.1016/j.jtrangeo.2014.08.007

[17] Japanese Government Statistics (2018) e-Stat of Foreign Residents in Japan, Table 17-12-02-2, December 2017. (in Japanese)

https://www.e-stat.go.jp/stat-search/files?page $=1$ \&layout $=$ datalist\&toukei $=0025001$ 2\&tstat $=000001018034 \&$ cycle $=1 \&$ year $=20170 \&$ month $=24101212 \&$ tclass $1=0000010$ 60399 
Appendix 1. Mean scores on the items in intercultural sensitivity scale $(n=156)$.

\begin{tabular}{|c|c|c|}
\hline Subscales & Items & Mean \\
\hline \multirow{7}{*}{$\begin{array}{l}\text { Interaction } \\
\text { Engagement }\end{array}$} & $\begin{array}{l}\text { I often show my culturally-distinct counterpart my understanding } \\
\text { through verbal or nonverbal cues. }\end{array}$ & $3.73 \pm 0.58$ \\
\hline & I enjoy interacting with people from different cultures. & $3.50 \pm 0.93$ \\
\hline & $\begin{array}{l}\text { I have a feeling of enjoyment towards differences between my } \\
\text { culturally-distinct counterpart and me. }\end{array}$ & $3.49 \pm 0.82$ \\
\hline & I avoid those situations where I will have to deal with culturally-distinct persons.* & $3.48 \pm 0.84$ \\
\hline & $\begin{array}{l}\text { I often give positive responses to my culturally-different counterpart } \\
\text { during our interacion. }\end{array}$ & $3.27 \pm 0.67$ \\
\hline & I am open-minded to people from different cultures. & $3.12 \pm 0.82$ \\
\hline & I tend to wait before forming an impression of culturally-distinct counterparts. & $2.79 \pm 0.84$ \\
\hline \multirow{6}{*}{$\begin{array}{l}\text { Respect for } \\
\text { Cultural Differences }\end{array}$} & I think people from other cultures are narrow-minded.* & $4.14 \pm 0.66$ \\
\hline & I would not accept the opinions of people from different cultures.* & $4.03 \pm 0.70$ \\
\hline & I respect the values of people from different cultures. & $3.81 \pm 0.71$ \\
\hline & I don't like to be with people from different cultures.* & $3.64 \pm 0.87$ \\
\hline & I respect the ways people from different cultures behave. & $3.57 \pm 0.65$ \\
\hline & I think my culture is better than other cultures. ${ }^{*}$ & $3.57 \pm 0.80$ \\
\hline \multirow{5}{*}{$\begin{array}{l}\text { Interaction } \\
\text { Confidence }\end{array}$} & I find it very hard to talk in front of people from different cultures.* & $2.32 \pm 1.06$ \\
\hline & $\begin{array}{l}\text { I can be as sociable as I want to be when interacting with people } \\
\text { from different cultures. }\end{array}$ & $2.21 \pm 0.89$ \\
\hline & I always know what to say when interacting with people from different cultures. & $2.08 \pm 0.87$ \\
\hline & I am pretty sure of myselt in interacting with people from different cultures. & $2.07 \pm 0.87$ \\
\hline & I feel confident when interacting with people from different cultures. & $1.97 \pm 0.83$ \\
\hline \multirow{3}{*}{$\begin{array}{l}\text { Interaction } \\
\text { Enjoyment }\end{array}$} & I often get discouraged when I am with people from different cultures.* & $3.90 \pm 0.85$ \\
\hline & I get upset easily when interacting with people from different cultures.* & $3.26 \pm 0.96$ \\
\hline & I often feel useless when interacting with people from different cultures.* & $2.60 \pm 1.01$ \\
\hline \multirow{3}{*}{$\begin{array}{c}\text { Interaction } \\
\text { Attentiveness }\end{array}$} & $\begin{array}{l}\text { I try to obtain as much information as I can when interacting with people } \\
\text { from different cultures. }\end{array}$ & $3.54 \pm 0.72$ \\
\hline & I am very observant when interacting with people from different cultures. & $3.20 \pm 0.77$ \\
\hline & $\begin{array}{l}\text { I am sensitive to my culturally-distinct conterpart's subtle meanings } \\
\text { during our interaction. }\end{array}$ & $3.06 \pm 0.74$ \\
\hline
\end{tabular}

Items indicated by ${ }^{*}$ are reverse items.

Appendix 2. Mean scores on the items in cultural competence in nursing scale $(n=156)$.

\begin{tabular}{lcc}
\hline Subscales & Items & Mean \\
\hline & $\begin{array}{c}\text { I understand the communication characteristics of Japanese } \\
\text { people. }\end{array}$ & $2.59 \pm 0.78$ \\
Awareness of one's own culture & $\begin{array}{c}\text { I take a daily interest in the behavioral characteristics of } \\
\text { Japanese people. }\end{array}$ & $2.58 \pm 0.80$ \\
& $\begin{array}{l}\text { I am interested in television programs and books that deal } \\
\text { with the subject of "Japanese people’s way of thinking." }\end{array}$ & $2.47 \pm 0.89$ \\
\hline
\end{tabular}




\section{Continued}

\begin{tabular}{|c|c|c|}
\hline \multirow{8}{*}{ Approach-avoidance tendency } & I believe that foreigners make this country less safe. ${ }^{*}$ & $2.96 \pm 0.83$ \\
\hline & I believe that the West is superior to Southeast Asia.* & $2.88 \pm 0.82$ \\
\hline & $\begin{array}{l}\text { When I hear the phrase "the best in the U.S.A," I believe it is } \\
\text { superior to "the best in Japan."* }\end{array}$ & $2.81 \pm 0.93$ \\
\hline & I feel stressed when providing nursing to foreign clients. ${ }^{*}$ & $2.58 \pm 0.80$ \\
\hline & I want to engage in nursing for foreign clients. & $2.26 \pm 0.75$ \\
\hline & $\begin{array}{l}\text { I prefer to avoid people who behave unpleasantly rather than } \\
\text { talk to them.* }\end{array}$ & $2.25 \pm 0.77$ \\
\hline & I feel that nursing foreign clients is rewarding. & $2.25 \pm 0.64$ \\
\hline & I feel anxious when providing nursing to foreign clients. ${ }^{*}$ & $1.92 \pm 0.71$ \\
\hline \multirow{5}{*}{ General cultural knowledge } & Different races and ethnicities have specific diseases. & $2.41 \pm 0.72$ \\
\hline & Metabolic function differs between races and ethnicities. & $2.25 \pm 0.70$ \\
\hline & Pharmacological effects differ between races and ethnicities. & $2.08 \pm 0.71$ \\
\hline & $\begin{array}{l}\text { How to assess different races and ethnicities taking into } \\
\text { account anatomical and physiological differences }\end{array}$ & $1.74 \pm 0.55$ \\
\hline & $\begin{array}{c}\text { Organizations, institutions, and groups that offer telephone } \\
\text { interpreting or free medical information services to } \\
\text { foreigners }\end{array}$ & $1.68 \pm 0.71$ \\
\hline \multirow{16}{*}{ Specific cultural knowledge } & $\begin{array}{l}\text { the most commonly encountered country of origin among } \\
\text { the foreign clients you have provided nursing care for }\end{array}$ & \\
\hline & The religion in that country & $2.17 \pm 0.75$ \\
\hline & The social conditions of that country & $2.12 \pm 0.72$ \\
\hline & The economic conditions of that country & $2.12 \pm 0.73$ \\
\hline & The diets in that country & $2.04 \pm 0.69$ \\
\hline & $\begin{array}{l}\text { Religious and customary taboos (contraindications)in that } \\
\text { country }\end{array}$ & $1.98 \pm 0.66$ \\
\hline & The social class composition of that country & $1.92 \pm 0.67$ \\
\hline & The educational situation of that country & $1.81 \pm 0.60$ \\
\hline & $\begin{array}{l}\text { Communication behaviors of people in that country } \\
\text { [i.e., individualism or collectivism, highly contextual } \\
\text { (the listener makes conjectures) or weakly contextual } \\
\text { (the speaker makes assertions), perception of promises, } \\
\text { perception of privacy, personal space, touching, } \\
\text { eye contact, etc.] }\end{array}$ & $1.81 \pm 0.63$ \\
\hline & Family and parental relationships in that country & $1.78 \pm 0.66$ \\
\hline & Male and female role awareness in that country & $1.77 \pm 0.66$ \\
\hline & The medical system of that country & $1.75 \pm 0.62$ \\
\hline & The moral consciousness in that country & $1.74 \pm 0.65$ \\
\hline & How people in that country interact with neighbors & $1.72 \pm 0.63$ \\
\hline & The health consciousness of people in that country & $1.72 \pm 0.64$ \\
\hline & $\begin{array}{l}\text { Customs surrounding pregnancy and childbirth in that } \\
\text { country }\end{array}$ & $1.65 \pm 0.71$ \\
\hline
\end{tabular}




\section{Continued}

The sense of time of people in that country

(i.e., Is emphasis in daily life placed on the past, present, or

$1.63 \pm 0.61$

future? Are people punctual?)

Common diseases in that country

$1.59 \pm 0.62$

Customs surrounding death of people in that country

$1.58 \pm 0.58$

Traditional folk remedies in that country

$1.52 \pm 0.56$

When a foreign client does not understand Japanese, I use a combination of speech and non-verbal gestures

$3.02 \pm 0.57$ and expressions to reduce the client's anxiety.

I ask for foreign clients' consent before performing procedures.

$2.86 \pm 0.69$

I check to make sure that foreign clients understand what we have told them.

$2.85 \pm 0.69$

I use simple, easily comprehensible Japanese expressions when speaking to foreign clients.

$2.85 \pm 0.65$

When I cannot follow the wishes of a foreign client, I discuss the reasons with the client while acknowledging their feelings and try to gain their understanding.

Cultural skills

When a foreign client does not understand Japanese, I use a translation table for foreign languages

$2.42 \pm 0.84$

When Japanese nursing methods differ from those of a

foreign client's country of origin, I ask for the client's opinion about their treatment.

I consider the religious and customary taboos (contraindications) of foreign clients.

I provide full explanations to foreign clients.

$2.08 \pm 0.78$

When Japanese nursing methods differ from those of a foreign client's country of origin, I explain why nursing is $2.04 \pm 0.82$ done in a particular manner in Japan.

I perform assessments taking into account the anatomical and physiological characteristics of foreign clients.

Items indicated by ${ }^{*}$ are reverse items. 